\title{
Influence of He-Ne laser therapy on the dynamics of wound healing in mice treated with anti-inflammatory drugs
}

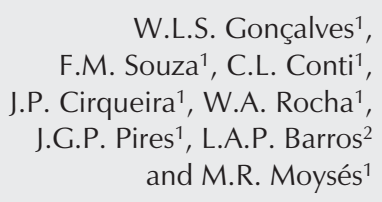

W.L.S. Gonçalves ${ }^{1}$, F.M. Souza ${ }^{1}$, C.L. Conti ${ }^{1}$, J.P. Cirqueira ${ }^{1}$, W.A. Rocha ${ }^{1}$, J.G.P. Pires ${ }^{1}$, L.A.P. Barros ${ }^{2}$ and M.R. Moysés ${ }^{1}$

${ }^{1}$ Departamento de Ciências Fisiológicas, ${ }^{2}$ Departamento de Clínica Odontológica, Centro de Ciências da Saúde, Universidade Federal do Espírito Santo, Vitória, ES, Brasil

\section{Correspondence \\ M.R. Moysés \\ Departamento de Ciências \\ Fisiológicas \\ Centro de Ciências da Saúde, UFES \\ Av. Marechal Campos, 1468 \\ 29040-755 Vitória, ES \\ Brasil \\ Fax + 55-27-3335-7330 \\ E-mail: mrmoyses@npd.ufes.br}

Research partially supported by UFES and CAPES.

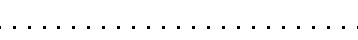

Received April 6, 2006 Accepted March 7, 2007

\begin{abstract}
We determined the effects of helium-neon (He-Ne) laser irradiation on wound healing dynamics in mice treated with steroidal and nonsteroidal anti-inflammatory agents. Male albino mice, 28-32 g, were randomized into 6 groups of 6 animals each: control (C), He-Ne laser (L), dexamethasone (D), D + L, celecoxib (X), and X + L. D and X were injected $i m$ at doses of 5 and $22 \mathrm{mg} / \mathrm{kg}$, respectively, $24 \mathrm{~h}$ before the experiment. A $1-\mathrm{cm}$ long surgical wound was made with a scalpel on the abdomens of the mice. Animals from groups $\mathrm{L}, \mathrm{D}+\mathrm{L}$ and $\mathrm{X}+$ $\mathrm{L}$ were exposed to $4 \mathrm{~J}\left(\mathrm{~cm}^{2}\right)^{-1} \mathrm{day}^{-1}$ of He-Ne laser for $12 \mathrm{~s}$ and were sacrificed on days 1,2, or 3 after the procedure, when skin samples were taken for histological examination. A significant increase of collagen synthesis was observed in group L compared with C (168 \pm 20 vs $63 \pm 8 \mathrm{~mm}^{2}$ ). The basal cellularity values on day 1 were: $\mathrm{C}=763$ $\pm 47, \mathrm{~L}=1116 \pm 85, \mathrm{D}=376 \pm 24, \mathrm{D}+\mathrm{L}=698 \pm 31, \mathrm{X}=453 \pm 29$, $\mathrm{X}+\mathrm{L}=639 \pm 32 \mathrm{U} / \mathrm{mm}^{2}$. These data show that application of $\mathrm{L}$ increases while $\mathrm{D}$ and $\mathrm{X}$ decrease the inflammatory cellularity compared with $C$. They also show that $\mathrm{L}$ restores the diminished cellularity induced by the anti-inflammatory drugs. We suggest that He-Ne laser promotes collagen formation and restores the baseline cellularity after pharmacological inhibition, indicating new perspectives for laser therapy aiming to increase the healing process when anti-inflammatory drugs are used.
\end{abstract}

\section{Introduction}

Morphological and biochemical studies in humans have revealed a sophisticated mechanism for skin wound healing, including replacement of the affected subcutaneous tissue with a new matrix and re-epithelization. Injury to the skin triggers a cascade of events including inflammation and tissue
Key words

- Photo-stimulation

- Skin

- Collagen

- Cyclooxygenase

- Corticosteroids

- Cicatrization

- Anti-inflammatory drugs remodeling, which eventually leads to total or partial restoration of the injured area $(1,2)$. Various aspects of this complex process have attracted the attention of researchers over the years, particularly the factors which may hinder it.

Vascular events, inflammatory cell migration/activation and synthesis of extracellular matrix components are known cellular 
processes intervening in the dynamics of wound repair $(3,4)$. The repairing process begins immediately after the injury through the release of cytokines, growth factors, some hormones, and several low-molecular weight substances from plasma or activated platelets (1-4). The main endogenous hormone involved in the dynamics of tissue repair is cortisol, which affects the metabolism of carbohydrates and proteins and exerts important anti-inflammatory effects $(5,6)$.

Recent studies have suggested that the early events in the wound healing process are the most appropriate for useful therapeutic interventions, while the most important repair failures are those occurring in the initial phase (3). In this respect, we should mention studies concerning the role of stress in the wound healing process, showing that endogenous cortisol down-regulates pro-inflammatory cytokine and chemokine expression, which reduces the inflammation edema, cellular recruitment and cell proliferation at the injured site (7-9).

Several experimental and clinical studies have evaluated the effects of helium-neon $(\mathrm{He}-\mathrm{Ne})$ laser therapy on the process of tissue regeneration in areas such as skin, bone, skeletal muscle, and the nervous system (1013), with contradictory results. However, based on clinical experience, some investigators have proposed that photo-stimulation with low-energy laser at certain wavelengths promotes tissue repair by releasing growth factors $(2,10-15)$.

Taking into account these controversies, we decided to investigate the possible beneficial effects of He-Ne laser irradiation on the skin repair process in mice previously treated with steroidal or non-steroidal anti-inflammatory drugs, which possibly are able to affect the release and/or the effects of factors involved in the tissue repair process $(9,10)$.

\section{Material and Methods}

Experiments were performed on adult male albino mice, weighing 28-32 g, from our breeding stock. The animals, 6 to a group, were housed in $0.30-\mathrm{m}^{2}$ cages under controlled conditions of 12-h light periods, temperature $\left(\sim 26^{\circ} \mathrm{C}\right)$ and minimal noise. Animals were allowed free access to filtered water and standard rat chow. All the experimental procedures adopted were in accordance with the International Guidelines for Animal Care.

\section{Experimental design}

The mice were randomly divided into 6 groups of 6 mice each: 1) control (C), 2) HeNe laser (L), 3) dexamethasone (D), 4) D + $\mathrm{L}, 5)$ celecoxib $(\mathrm{X})$, and 6) $\mathrm{X}+\mathrm{L}$. These groups were further divided into 24-, 48and 72-h groups. D and $\mathrm{X}$ were injected intramuscularly $(\mathrm{im})$ at doses of 5 and 22 $\mathrm{mg} / \mathrm{kg}$, respectively, $24 \mathrm{~h}$ before the beginning of the experiment.

A surgical skin wound was made with a scalpel on the abdomen of the mice who were under general anesthesia with $10 \mathrm{mg} /$ $\mathrm{kg}$ ketamine $+20 \mathrm{mg} / \mathrm{kg}$ xylazine, $\mathrm{im}$. The skin on the abdominal region was shaved before the procedure using an aseptic technique. The surgical incision was standardized as follows: 1-cm length (xiphoid appendix as reference) and adequate depth to include the epidermis, dermis and abdominal fascia. After the surgical procedure, laser irradiation was applied (see below) to the treated groups. The animals were then returned to their home cages.

\section{Laser treatment}

A laser device (KLD-Biosystem ${ }^{\circledR}$, São Paulo, SP, Brazil) containing a continuouswave He-Ne light emitting at $633 \mathrm{~nm}$ and 5 $\mathrm{mW}$ output was used. Power output was calibrated by a power meter. In order to determine the duration of cutaneous applications, the spot size $(1.5 \mathrm{~cm})$ was measured and the quantity of energy density and power 
output were determined using the Tuner and Hode equation (16). Each animal in the laser groups received a fixed daily dose of $\mathrm{He}-\mathrm{Ne}$ laser irradiation at an energy density of $4 \mathrm{~J} /$ $\mathrm{cm}^{2}$ applied over a period of $12 \mathrm{~s}$. The laser probe was positioned to contact the wound. Only one session of laser was applied immediately after surgery.

The animals were then submitted to euthanasia by ethyl ether inhalation at 24,48 , and $72 \mathrm{~h}$ after the procedures and skin samples were removed for histological and morphometric analysis.

\section{Histological and morphometric analysis}

All skin lesion samples obtained were immediately fixed in $10 \%$ buffered formalin, $\mathrm{pH} 7$, for at least $24 \mathrm{~h}$. After fixation, the samples were gradually dehydrated in increasing ethanol concentrations ( 70 to $100 \%$ ), cleared in xylene and embedded in paraffin according to routine histological methods. The paraffin-embedded fragments were cut with an "820" Spence microtome (New York, NY, USA) and 6- $\mu$ m thick sections were obtained. Pairs of histological slides were kept in an incubator to dry and the sections were then stained with hematoxylin-eosin and Masson's trichrome for histological analysis.

The histology scoring was based on the degree of cellular invasion (cellularity), granulation tissue formation, vascularity, and re-epithelization. The code describing each animal's treatment was broken after the pathologist completed the scoring and ranking (Table 1).

Histomorphometry was performed using images captured and evaluated by a computerized Sigma-pro ${ }^{\circledR i m a g e}$ (St. Louis, MO, USA) capture system. Images were captured from five randomly chosen optical microscopic fields for each histological slide pair using the digital camera (total magnification 100 and 200X) from an Olympus ${ }^{\circledR}$ AX70 Plus microscope (Tokyo, Japan). The images were stored and submitted to a count of inflammatory cells or cellularity (i.e., cellular density) and analysis of collagen formation and of re-epithelization of the ulcerated areas of the wounds at the end of the experiment using digital marking (color contrast) as the discriminating parameter.

\section{Drugs}

Dexamethasone phosphate salt (Dexazona $^{\mathrm{TM}}$, Bunker, São Paulo, SP, Brazil) and celecoxib (COX-2 inhibitor; a kind donation from Pfizer, Guarulhos, SP, Brazil) were used. Doses were chosen according to those usually reported in the literature. Ketamine hydrochloride (Ketamin ${ }^{\mathrm{TM}}$, 5\% solution) was purchased from Cristalia (São Paulo, SP, Brazil). A commercial veterinary preparation of xylazine hydrochloride (Rompun ${ }^{\mathrm{TM}}$, Bayer, Rio de Janeiro, RJ, Brazil) was used. The two drugs were placed in the same syringe for anesthesia.

\section{Statistical analysis}

The nature of the variables studied or the variability of the means was considered using the biostatistics software GraphPad Prism 4. Unless otherwise stated, data were analyzed statistically by ANOVA followed by the Tukey test for multiple comparisons or the Mann-Whitney U-test for independent samples, as appropriate. The level of significance was set at $\mathrm{P}<0.05$.

Table 1. Histological scoring.

\begin{tabular}{ll}
\hline Score & Criteria \\
\hline $1-3$ & $\begin{array}{l}\text { None to minimal cell accumulation. No granulation tissue or epithelial } \\
\text { migration. }\end{array}$ \\
Thin, immature granulation dominated by inflammatory cells but showing \\
fibroblasts, capillaries, or collagen deposition. Minimal epithelial migration. \\
M-9 & $\begin{array}{l}\text { Moderately thick granulation tissue can range from being dominated by } \\
\text { inflammation cells to more fibroblast and collagen deposition. Extensive } \\
\text { neovascularization. Epithelium can range from minimal to moderate } \\
\text { migration. } \\
\text { Thick, vascular granulation tissue dominated by fibroblasts and extensive } \\
\text { collagen deposition. Epithelium partially to completely lining the wound. }\end{array}$ \\
&
\end{tabular}




\section{Results}

Clinical inspection of skin lesion samples showed a regular amount of humid clot on the surface and the presence of many blood vessels in the wound area in the $C$ and $D$ groups, but not in the other four groups (L, D + L, X, X + L; data not shown).

The morphological criteria used for scoring the material are presented in Table 1. Histological analysis showed that specimens from the laser groups $(\mathrm{L}, \mathrm{D}+\mathrm{L}, \mathrm{X}+\mathrm{L})$ had fewer blood clots and displayed more accelerated re-epithelization, granulation tissue formation and capillary proliferation than
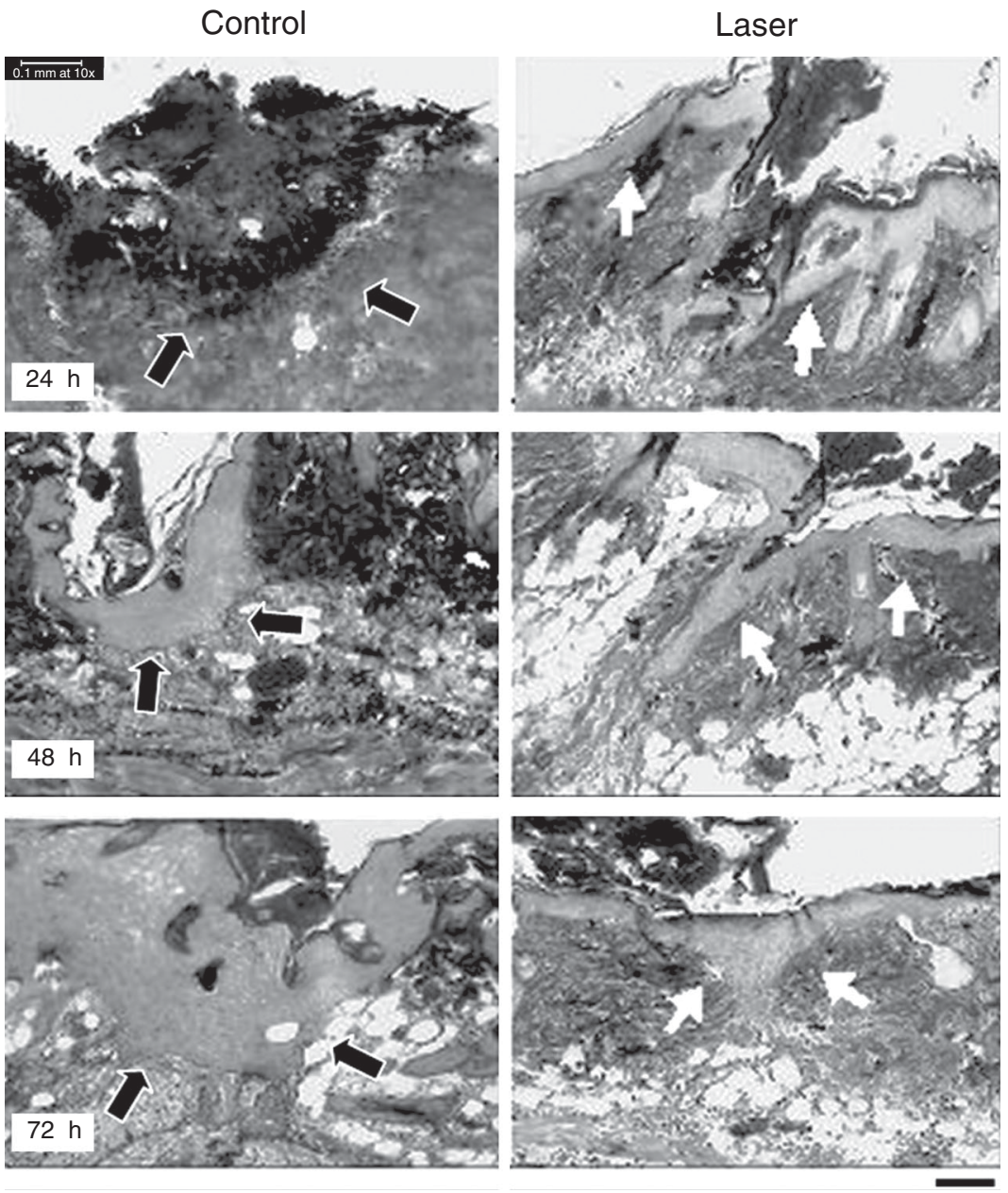

Figure 1. Photomicrograph of the skin wound of control (left, black arrows) and laser therapy (right, white arrows) groups at 24,48 , and $72 \mathrm{~h}$. The white arrows show an accelerated healing process induced by He-Ne laser in the experimental groups (Masson's trichrome; scale bar: $0.1 \mathrm{~mm}$ at $10 \mathrm{X}$ ). the other groups, such as $\mathrm{C}$ (Figure 1). Based on these morphological criteria (Table 1), it was observed that the $\mathrm{L}$ group displayed important healing dynamics after $24 \mathrm{~h}$ of treatment compared to the $\mathrm{C}$ group. Lasertreated animals showed significantly higher histological scores than the respective controls, in the first $24 \mathrm{~h}(7.16$ vs $1.38 ; \mathrm{P}<$ 0.0001, Mann-Whitney U-test).

As shown in Figure 2A, the epithelium samples from the $\mathrm{D}\left(7.3 \pm 0.7 \mathrm{~mm}^{2}\right)$ and $\mathrm{X}$ $\left(17.1 \pm 0.8 \mathrm{~mm}^{2}\right)$ groups showed expected significant differences during the first $24 \mathrm{~h}$ when compared to the $\mathrm{C}$ group $(12.6 \pm 0.8$ $\mathrm{mm}^{2}$ ). D significantly reduced re-epithelization, while, surprisingly, $\mathrm{X}$ increased it. In the $\mathrm{D}+\mathrm{L}$ group, laser irradiation restored the re-epithelization phenomenon (15.0 \pm $0.4 \mathrm{~mm}^{2}$ ), whereas in the $\mathrm{X}+\mathrm{L}$ group, laser application further decreased the phenomenon $\left(11.0 \pm 0.4 \mathrm{~mm}^{2}\right)$. In addition, the $\mathrm{L}$ group showed that laser irradiation produced a significant increase $\left(17.3 \pm 0.8 \mathrm{~mm}^{2}\right)$ in the wound re-epithelization (Figure 2A).

Collagen synthesis was significantly higher in the $\mathrm{L}\left(168 \pm 20 \mathrm{~mm}^{2}\right), \mathrm{D}+\mathrm{L}(189$ $\left.\pm 11 \mathrm{~mm}^{2}\right)$, and $\mathrm{X}+\mathrm{L}\left(185 \pm 9 \mathrm{~mm}^{2}\right)$ groups (Figure 2B) and slightly but significantly attenuated in the $\mathrm{D}$ and $\mathrm{X}$ groups compared with $C$ animals $(56 \pm 6,55 \pm 5$, and $62 \pm 8$ $\mathrm{mm}^{2}$, respectively).

As expected, D or X caused a significant reduction in cellularity compared with $\mathrm{C}$ during the first $24 \mathrm{~h}(375 \pm 24,452 \pm 29$, and $763 \pm 48 \mathrm{U} / \mathrm{mm}^{2}$ for $\mathrm{D}, \mathrm{X}$, and $\mathrm{C}$, respectively). Laser therapy restored cellularity to the baseline level, as seen in the $\mathrm{D}+\mathrm{L}(688 \pm 31$ $\left.\mathrm{U} / \mathrm{mm}^{2}\right)$ and $\mathrm{X}+\mathrm{L}\left(639 \pm 32 \mathrm{U} / \mathrm{mm}^{2}\right)$ groups (Figure 2C). In these two groups, laser application also increased the migration and mobility of leukocytes and fibroblasts/myoblasts (Figure 3).

\section{Discussion}

Low-intensity laser therapy is recognized as an effective therapeutic method by the 
FDA, particularly to improve tissue healing (3-6). A large body of evidence from in vitro and in vivo studies has suggested that LILT enhances collagen synthesis $(4-6,10)$, increases the motility of keratinocytes (17), releases growth factors $(15,17)$, and promotes the transformation of fibroblasts into myofibroblasts $(4-6,15,17-19)$. On the other hand, the idea of investigating the early phase of the skin repair process under the influence of anti-inflammatory agents (a corticosteroid or a cyclooxygenase (COX-2) inhibitor) was based on the known pharmacological properties of such drugs and on their broad clinical use and side-effects (20-24).

Studies have shown that during normal wound healing the inflammatory phase lasts up to two days $(3,24-26)$. Cell proliferation, epithelization, granulation tissue formation, and wound contraction occur during the proliferative phase. Growth of new epithelial cells across the surface of the wound and collagen remodeling occur during the maturation phase of wound healing, which lasts for months or even longer. The present results showed that He-Ne laser irradiation of the skin of mice produced beneficial effects on the macroscopic aspects of the surgical wound, such as reduction of humidity, apparent vascular modulation and effective control of the amount of clot in the injured area, during the first $24 \mathrm{~h}$. These data therefore, suggest that laser therapy increased the healing dynamics compared to control.

Werner and Grose (26) described three different stages of wound repair: i) 12-24 h after injury the wounded area is filled with a blood clot which is invaded by neutrophils; ii) at days 3-7 after injury, most neutrophils have undergone apoptosis whereas macrophages are abundant in the wound tissue at this stage of repair. Endothelial cells migrate into the clot, proliferate and form new blood vessels. Fibroblasts migrate into the wound tissue, where they proliferate and deposit extracellular matrix. The new tissue is called granulation tissue. Keratinocytes proliferate

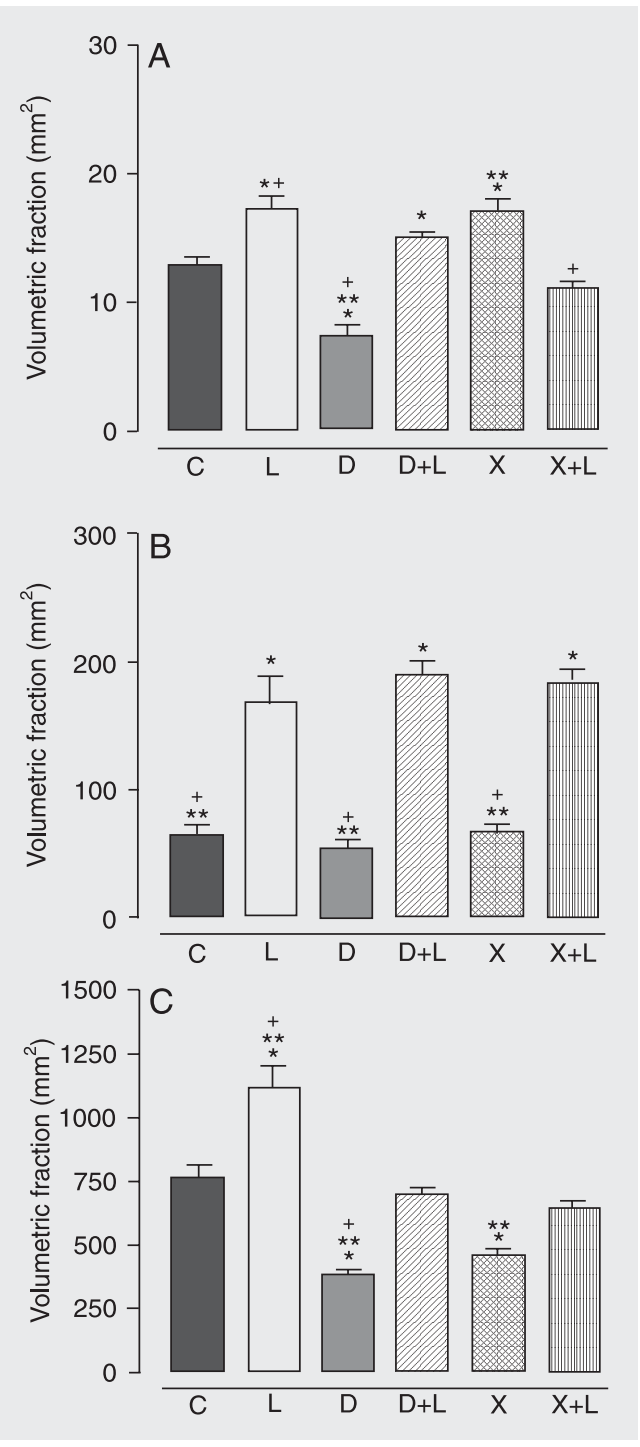

Figure 2. Determinations of the volumetric fractions of the epithelium $(A)$, collagen $(B)$, and cellularity $(\mathrm{C}$; neutrophils and fibroblasts/myofibroblasts) of mouse skin $24 \mathrm{~h}$ after treatments. $\mathrm{C}=$ control; $\mathrm{L}=\mathrm{He}-\mathrm{Ne}$ laser; $\mathrm{D}=$ steroidal anti-inflammatory drug dexamethasone; $\mathrm{D}+\mathrm{L}=$ dexamethasone plus laser; $X=$ non-steroidal anti-inflammatory drug celecoxib; $X+L$ $=$ celecoxib plus laser. Data are reported as mean \pm SEM. ${ }^{*} \mathrm{P}<$ 0.01 vs $\mathrm{C} ;{ }^{* *} \mathrm{P}<0.01$ vs $\mathrm{D}+\mathrm{L} ;{ }^{+} \mathrm{P}$ $<0.05$ vs $\mathrm{X}+\mathrm{L}$ (Tukey test).

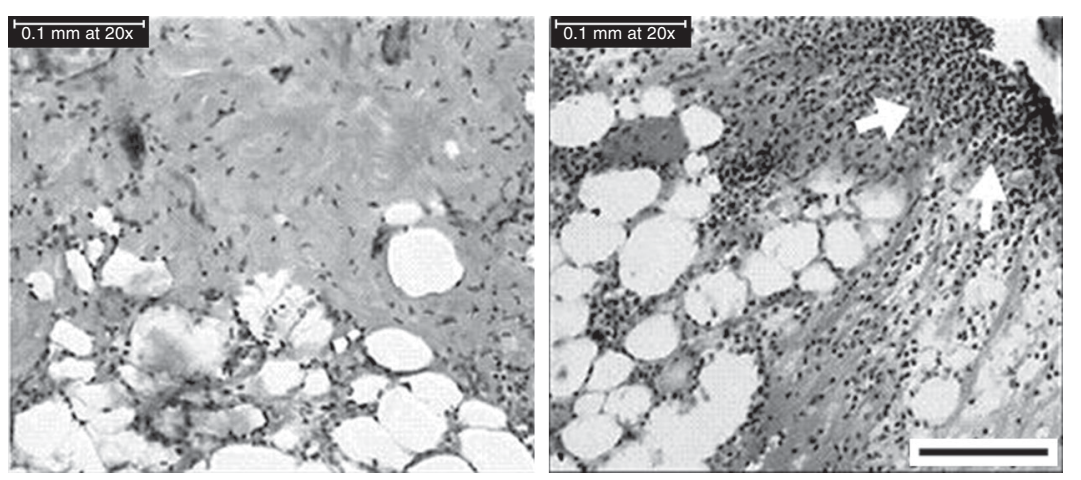

Figure 3. Photomicrography of the skin wound in the dexamethasone $(A)$ and dexamethasone + laser groups (B) at $24 \mathrm{~h}$. The white arrows point to increased cellularity with the intense presence of mononuclear cells in the infiltrate, predominantly fibroblasts and neutrophils in the skin wound margins (H\&E; scale bar: $0.1 \mathrm{~mm}$ at $20 \mathrm{X}$ ). 
at the wound edge and migrate down the injured dermis and above the provisional matrix; iii) 1-2 weeks after injury the wound is completely filled with granulation tissue. Fibroblasts have transformed into myofibroblasts, leading to wound contraction and collagen deposition. The wound is then completely covered with a neoepidermis.

The time course of the present results obtained from histological analysis of the $\mathrm{C}$ group fit with the picture described by Werner and Grose (26). However, morphological analysis of the laser therapy groups indicates that significant differences do exist in these groups, suggesting an acceleration of the healing dynamics during the first days caused by laser application.

Similar results were obtained by Maiya et al. (15) in diabetic rats, showing that lasertreated animals healed faster and better than controls. Other studies $(11,12,14,18,22)$ using He-Ne low-energy laser have indicated that it is mainly the laser energy at $633 \mathrm{~nm}$ wavelength that affects the healing dynamics, producing changes in the early phase of the repair process, i.e., the inflammatory phase.

In the first hours of healing, the repair events are directed towards preventing subsequent blood loss (hemostasis) and towards the formation of a fibrin plug that supplies the preliminary matrix for the subsequent processes in which platelets adhere to the collagen in the perivascular space. Such contact activates platelets, which releases bioactive factors that accelerate the migration and proliferation of fibroblasts, a key cell in this process $(11,12)$.

The suggestion that laser affects the early events in the dynamics of wound healing was partially based on the observed lowintensity laser therapy-induced attenuation of reactive oxygen species production by neutrophils in inflammatory models. This was initially suggested by the study of Fujimaki et al. (20), who described a diminished oxidative stress-induced apoptosis of neutrophils in acute inflammation (20,2728). Nevertheless, the basic aspects of oxidative stress and the mechanisms by which reactive oxygen species modulate physiological and pathological processes, with emphasis on wound healing, are still motive of debate.

As stated before, the early events in wound healing, with special reference to the inflammatory phase, are crucial for the success of the process, as suggested by studies on the effects of anti-inflammatory drugs (3). It is well known that corticosteroids down-regulate pro-inflammatory proteins and affect gene expression, interfering with almost all phases of the inflammatory process (7-9). On the other hand, controlled laboratory trials have reported that laser photostimulation can reduce inflammation through inhibition of inducible COX-2, leading to a reduction in prostanoid levels $(28,29)$. Additionally, experiments involving various cell culture stages have shown that laser irradiation at early stages significantly stimulates cell proliferation, alkaline phosphatase activity and osteocalcin gene expression, indicating that laser photostimulation enhances bone formation in vitro $(3,11,19)$.

The present data (Figure 2B) agree with those reported by others $(3,11-24)$, showing that He-Ne $(633 \mathrm{~nm})$ laser application induces a more mature scar, displaying collagen fibers arranged in parallel. Our results also show that the presence of an anti-inflammatory drug, either a steroidal or a nonsteroidal drug, does not inhibit the biostimulatory effects of laser photostimulation. It should be mentioned that re-epithelization increased during the first $24 \mathrm{~h}$ in the $\mathrm{He}-\mathrm{Ne}$ laser-treated animals, suggesting an enhancement of keratinocytes production, even in the presence of dexamethasone. Interestingly, celecoxib (X; a COX-2 inhibitor) increased the re-epithelization phenomenon, which was restored to baseline levels after $\mathrm{He}-\mathrm{Ne}$ laser irradiation (Figure 2A). Concomitantly, the cellularity counts showed important effects 
produced by $\mathrm{He}-\mathrm{Ne}$ irradiation in the presence of D or X towards the maintenance of inflammatory cells at the "baseline" level (Figure 2C). It should be mentioned that recent studies $(30,31)$ have shown that $\mathrm{He}$ $\mathrm{Ne}$ laser irradiation can effectively accelerate the expression of tumor growth factor $\beta 1$ and facilitate changes in leukocyte activity and accumulation of lipids by oxidation products. Furthermore, tumor growth factor $\beta 1$ is a chemoattractant for neutrophils, macrophages and fibroblasts (18) and is also associated with the wound healing defect seen in glucocorticoid-treated animals (26).

Thus, the present findings suggest that the stimulatory effects of laser photostimulation are related to specific events during the first two phases of wound healing, i.e., the inflammatory phase and the proliferative phase, indicating that the time of intervention may be critical and also suggesting that satellite cells are major irradiation-responsive candidates. The present results show that He-Ne laser therapy can influence the behavior of many inflammatory cell types, and that multiple effects can occur simultaneously and accelerate healing dynamics in the presence of corticosteroids or non-steroidal anti-inflammatory drugs. Additionally, our results suggest that $\mathrm{He}-\mathrm{Ne}$ laser irradiation modulates the early phases of the repair process in vivo. We speculate that this could be due to biochemical events in the mitochondrial oxidation process and/or to accumulation of lipid by oxidation products. However, much more research using selective inhibitors and markers will be need to elucidate the exact mechanisms of action of laser photostimulation at the cellular and molecular levels.

\section{Acknowledgments}

The authors thank Dr. C.A. Redins, Dr. M.A.S. Novaes and Mrs. L. Bressoni (UFES, Vitória) for help with the techniques and morphological analysis.

\section{References}

1. Ishida $\mathrm{Y}$, Watanabe $\mathrm{H}$. Structural study of wound healing in mouse skin with special reference to quantitative changes of cellular constituents. Yamagata Med J 1999; 17: 332-342.

2. Werner S, Grose R. Regulation of wound healing by growth factors and cytokines. Physiol Rev 2003; 83: 835-870.

3. Reddy GK. Photobiological basis and clinical role of low-intensity lasers in biology and medicine. J Clin Laser Med Surg 2004; 22: 141-150.

4. Medrado AR, Pugliese LS, Reis SR, Andrade ZA. Influence of low level laser therapy on wound healing and its biological action upon myofibroblasts. Lasers Surg Med 2003; 32: 239-244.

5. Campana V, Moya M, Gavotto A, Juri H, Palma JA. Effects of diclofenac sodium and He:Ne laser irradiation on plasmatic fibrinogen levels in inflammatory processes. J Clin Laser Med Surg 1998; 16: 317-320.

6. Pessoa ES, Melhado RM, Theodoro LH, Garcia VG. A histologic assessment of the influence of low-intensity laser therapy on wound healing in steroid-treated animals. Photomed Laser Surg 2004; 22: 199-204.

7. Mercado AM, Padgett DA, Sheridan JF, Marucha PT. Altered kinetics of IL-1 alpha, IL-1 beta, and KGF-1 gene expression in early wounds of restrained mice. Brain Behav Immun 2002; 16: 150-162.

8. Sheridan JF, Padgett DA, Avitsur R, Marucha PT. Experimental models of stress and wound healing. World J Surg 2004; 28: 327330.

9. Pruzanski W, Vadas P. Phospholipase A2 - a mediator between proximal and distal effectors of inflammation. Immunol Today 1991; 12: 143-146.

10. Posten W, Wrone DA, Dover JS, Arndt KA, Silapunt S, Alam M. Lowlevel laser therapy for wound healing: mechanism and efficacy. Dermatol Surg 2005; 31: 334-340.

11. de Carvalho PT, Mazzer N, Barbieri CH, Siqueira JFR. Morphometric analysis of the percentage of collagen and number of macrophages highlighted by immunohistochemistry, in cutaneous wound in diabetic and non-diabetics rats treated through $\mathrm{He}-\mathrm{Ne}$ laser. Lasers Med Sci 2003; 18 (Suppl 1): S0167 (Abstract).

12. de Carvalho PT, Mazzer N, dos Reis FA, Belchior AC, Silva IS. Analysis of the influence of low-power He-Ne laser on the healing of skin wounds in diabetic and non-diabetic rats. Acta Cir Bras 2006; 21: 177-183.

13. Amaral AC, Parizotto NA, Salvini TF. Dose-dependency of lowenergy $\mathrm{HeNe}$ laser effect in regeneration of skeletal muscle in mice. Lasers Med Sci 2001; 16: 44-51.

14. Pugliese LS, Medrado AP, Reis SR, Andrade ZA. The influence of low-level laser therapy on biomodulation of collagen and elastic fibers. Pesqui Odontol Bras 2003; 17: 307-313. 
15. Maiya GA, Kumar P, Rao L. Effect of low intensity helium-neon (He$\mathrm{Ne}$ ) laser irradiation on diabetic wound healing dynamics. Photomed Laser Surg 2005; 23: 187-190.

16. Tuner J, Hode L. It's all in the parameters: a critical analysis of some well-known negative studies on low-level laser therapy. J Clin Laser Med Surg 1998; 16: 245-248.

17. Rood PA, Haas AF, Graves PJ, Wheeland RG, Isseroff RR. Lowenergy helium neon laser irradiation does not alter human keratinocyte differentiation. J Invest Dermatol 1992; 99: 445-448.

18. Rocha AM Jr, Oliveira RG, Farias RE, Andrade LCR, Aarestrup FM. Modulation of fibroblast proliferation and inflammatory response by low-intensity laser in tissue repair process. An Bras Dermatol 2006; 81: 150-156.

19. Hawkins $\mathrm{DH}$, Abrahamse $\mathrm{H}$. The role of laser fluence in cell viability, proliferation, and membrane integrity of wounded human skin fibroblasts following helium-neon laser irradiation. Lasers Surg Med 2006; 38: 74-83.

20. Fujimaki Y, Shimoyama T, Liu Q, Umeda T, Nakaji S, Sugawara K. Low-level laser irradiation attenuates production of reactive oxygen species by human neutrophils. J Clin Laser Med Surg 2003; 21 : 165-170.

21. Jiang $Y$. Thirty cases of sub-healthy state regulated by acupuncture and He-Ne laser vascular irradiation. J Tradit Chin Med 2006; 26 : 102-103.

22. Lan CC, Wu CS, Chiou MH, Hsieh PC, Yu HS. Low-energy heliumneon laser induces locomotion of the immature melanoblasts and promotes melanogenesis of the more differentiated melanoblasts: recapitulation of vitiligo repigmentation in vitro. J Invest Dermatol
2006; 126: 2119-2126.

23. Simunovic Z, Ivankovich AD, Depolo A. Wound healing of animal and human body sport and traffic accident injuries using low-level laser therapy treatment: a randomized clinical study of seventy-four patients with control group. J Clin Laser Med Surg 2000; 18: 67-73.

24. Limpanichkul W, Godfrey K, Srisuk N, Rattanayatikul C. Effects of low-level laser therapy on the rate of orthodontic tooth movement. Orthod Craniofac Res 2006; 9: 38-43.

25. Singer AJ, Clark RA. Cutaneous wound healing. N Engl J Med 1999; 341: 738-746.

26. Werner S, Grose R. Regulation of wound healing by growth factors and cytokines. Physiol Rev 2003; 83: 835-870.

27. Rojkind M, Dominguez-Rosales JA, Nieto N, Greenwel P. Role of hydrogen peroxide and oxidative stress in healing responses. Cell Mol Life Sci 2002; 59: 1872-1891.

28. Muller-Decker K. Cyclooxygenases in the skin. J Dtsch Dermatol Ges 2004; 2: 668-675.

29. Sakurai $Y$, Yamaguchi M, Abiko Y. Inhibitory effect of low-level laser irradiation on LPS-stimulated prostaglandin E2 production and cyclooxygenase-2 in human gingival fibroblasts. Eur J Oral Sci 2000; 108: 29-34.

30. Sun $X H$, Wang $R$, Zhang XY. Effects of He-Ne laser irradiation on the expression of transforming growth factor beta1 during experimental tooth movement in rabbits. Shanghai Kou Qiang Yi Xue 2006; 15: 52-57.

31. Klebanov GI, Chichuk TV, Osipov AN, Vladimirov I. The role of lipid peroxidation products in the effect of He-Ne laser on human blood leukocytes. Biofizika 2005; 50: 862-866. 